Article

\title{
Label-Free Amperometric Immunosensor Based on Versatile Carbon Nanofibers Network Coupled with Au Nanoparticles for Aflatoxin $B_{1}$ Detection
}

\author{
Yunhong Huang ${ }^{1,2}$, Fei Zhu ${ }^{2}$, Jinhua Guan ${ }^{2}$, Wei Wei ${ }^{1, *}$ and Long Zou ${ }^{1,2, *(D)}$ \\ 1 State Key Laboratory for Managing Biotic and Chemical Threats to the Quality and Safety of Agro-Products, \\ Institute of Agro-Product Safety and Nutrition, Zhejiang Academy of Agricultural Sciences, \\ Hangzhou 310021, China; sallyyunhong@jxnu.edu.cn \\ 2 Nanchang Key Laboratory of Microbial Resources Exploitation \& Utilization from Poyang Lake Wetland, \\ College of Life Sciences, Jiangxi Normal University, Nanchang 330022, China; zhufei@jxnu.edu.cn (F.Z.); \\ guanjh@jxnu.edu.cn (J.G.) \\ * Correspondence: weiwei@zaas.ac.cn (W.W.); zoulong@jxnu.edu.cn (L.Z.)
}

Citation: Huang, Y.; Zhu, F.; Guan, J.; Wei, W.; Zou, L. Label-Free

Amperometric Immunosensor Based on Versatile Carbon Nanofibers Network Coupled with Au Nanoparticles for Aflatoxin $\mathrm{B}_{1}$ Detection. Biosensors 2021, 11, 5 . https://dx.doi.org/10.3390/ bios11010005

Received: 28 November 2020 Accepted: 23 December 2020 Published: 24 December 2020

Publisher's Note: MDPI stays neutral with regard to jurisdictional claims in published maps and institutional affiliations.

Copyright: () 2020 by the authors. Licensee MDPI, Basel, Switzerland. This article is an open access article distributed under the terms and conditions of the Creative Commons Attribution (CC BY) license (https: / / creativecommons.org/ licenses/by/4.0/).

\begin{abstract}
Facile detection methods for mycotoxins with high sensitivity are of great significance to prevent potential harm to humans. Herein, a label-free amperometric immunosensor based on a 3-D interconnected carbon nanofibers (CNFs) network coupled with well-dispersed Au nanoparticles (AuNPs) is proposed for the quantitative determination of aflatoxin $\mathrm{B}_{1}\left(\mathrm{AFB}_{1}\right)$ in wheat samples. In comparison to common carbon nanotubes (CNTs), the CNFs network derived from bacterial cellulose biomass possesses a unique hierarchically porous structure for fast electrolyte diffusion and a larger electrochemical active area, which increases the peak current of differential pulse voltammetry curves for an immunosensor. Combined with AuNPs that are incorporated into CNFs by using linear polyethyleneimine (PEI) as a soft template, the developed Au@PEI@CNFs-based immunosensor showed a good linear response to $\mathrm{AFB}_{1}$ concentrations in a wide range from 0.05 to $25 \mathrm{ng} \mathrm{mL}^{-1}$. The limit of detection was $0.027 \mathrm{ng} \mathrm{mL}^{-1}(\mathrm{~S} / \mathrm{N}=3)$, more than three-fold lower than that of an Au@PEI@CNTs-based sensor. The reproducibility, storage stability and selectivity of the immunosensor were proved to be satisfactory. The developed immunosensor with appropriate sensitivity and reliable accuracy can be used for the analysis of wheat samples.
\end{abstract}

Keywords: aflatoxin $\mathrm{B}_{1}$; immunosensor; carbon nanofibers; Au nanoparticles; electrochemical detection

\section{Introduction}

Aflatoxins, as the toxic metabolites of Aspergillus flavus, A. nomius and A. parasiticus, are well known to be severely harmful to human beings and animals since they are highly carcinogenic, teratogenic and hepatotoxic [1,2]. Across the world, many agricultural and food products such as peanut, maize, wheat, rice and soybean are naturally contaminated by aflatoxins during the periods of growth, harvest and storage [3]. Particularly, the hot and humid weather in the southwest and south of China is highly favorable to aflatoxin contamination, which has become a serious threat to human health and an economic barrier [4]. Among more than twenty identified aflatoxins, aflatoxin $B_{1}\left(A_{F} B_{1}\right)$ is the most toxic and has been regarded as a group I carcinogen by the International Agency for Research on Cancer. Meanwhile, regulatory limits are enforced in many countries and regions for $\mathrm{AFB}_{1}$ levels to avoid its overexposure to human and animals. In China, the maximum allowed $\mathrm{AFB}_{1}$ level is as low as $5 \mu \mathrm{g} \mathrm{kg}^{-1}$ for many types of cereals (China National Standard No. GB 2761-2017) [5]. The European Union sets a limit of $2 \mu \mathrm{g} \mathrm{kg}^{-1}$ on $\mathrm{AFB}_{1}$ in cereals, nuts and their processed products (European Commission Regulation No. 1881/2006/EC) [6]. With the increasing concerns and the intensifying legislative framework about $\mathrm{AFB}_{1}$ worldwide, an efficient analytical method capable of simple, rapid and sensitive detection in food or other edibles is of crucial importance. 
Currently, several chromatography-based analytical techniques, including but not limited to high-performance liquid chromatography (HPLC) [7-9] and liquid chromatographytandem mass spectrometry (HPLC-MS) [10-12], have been developed as standard methodologies for the quantitative determination of $\mathrm{AFB}_{1}$ with high sensitivity and accuracy. However, these methodologies generally rely on well-equipped laboratory facilities, timeconsuming sample pretreatment and skilled operators, thereby rending them ineligible for rapid screening of large amounts of actual samples. [13] Meanwhile, immunoassay-based methods, for example enzyme-linked immunosorbent assay (ELISA) [14], immunochromatographic strip (ICS) $[15,16]$ and dot-immunochromatography flow through assay strip (DIGFA) [17], have been documented significantly for $\mathrm{AFB}_{1}$ detection over the past few decades owing to reliable sensitivity, excellent selectivity and suitability for highthroughput screening. In particular, electrochemical immunosensors that incorporate ultrasensitive electrochemical signals into immunological recognition depending on specific antibody-antigen interactions have attracted extensive interests. [18] For all we know, the construction of a well-defined functional electrode interface for signal amplification, together with enhanced stability, is a critical aspect for the development of electrochemical immunosensors. Functional nanomaterials such as nanostructured noble metals (e.g., gold nanoparticles, AuNPs) have powerful benefits in this direction on account of their features of high conductivity, excellent catalytic activity, etc. [19-23] In addition, apart from electrochemical immunosensors, AuNPs have been in other types of biosensors including, but not limited to, colorimetry [17,24,25], chemiluminescence [26], fluorescence [27] and surface plasmon resonance (SPR) $[28,29]$ analyses because of their flexible features and high biocompatibility. Notably, pure nanoparticles commonly tend to aggregate during application, possibly leading to low practicability. As an effective approach, the incorporation of AuNPs into nanostructured carbon substrates, with large surface area and remarkable conductivity, is the most commonly used route to improve electrochemical performance. [30] Diverse aspects of carbon nanomaterials, including 0-D carbon dots [31,32], 1-D carbon nanotubes [33-35] and 2-D graphene [36,37], have been documented widely. Moreover, 3-D carbon nanomaterials with a hierarchical porous structure have demonstrated significant achievements in developing an effective electron exchange interface for both energy conversion and electrochemical sensing $[38,39]$. Such a 3-D porous nanostructure not only provides a highly interconnected electron transfer network and extraordinarily large electrochemical-active area, but also allows fast electrolyte diffusion.

In our previous work, we fabricated a novel nano carbon network consisting of carbon nanofibers (CNFs) derived from bacterial celluloses (a special biomass product from microbial synthesis) for rationally functionalizing bioelectrodes [40]. Because of its unique 3-D hierarchically porous structure, constructed by cross-linked nanofibers with a diameter of 10-30 nm, and excellent biocompatibility, the bio-abiotic interfacial electron exchange improved dramatically when used to wire biological molecules onto electrodes, thereby leading to both high-powered bioelectricity production in microbial fuel cells and high-sensitive enzyme sensors $[40,41]$. Taken together, the bacterial celluloses-derived CNFs could be promising candidates to tailor an electrode interface for high-performance biosensors on account of their 3-D porous structure and superior biocompatibility. Herein, we attempt to develop a simple, sensitive and stable electrochemical immunosensor based on an AuNP-decorated CNFs network for rapid detection of $\mathrm{AFB}_{1}$. The hybrid electrode material was synthesized through the in-situ growth of AuNPs on interconnected carbon nanofibers with the help of linear polyethyleneimine (PEI) as a soft template according to a previous report [42], and its electrochemical properties were investigated carefully in comparison to AuNPs-modified CNTs as a control. Afterwards, an amperometric immunosensor for quantifying $\mathrm{AFB}_{1}$ was established and optimized, then confirmed by recovery in spiked wheat samples. This work is expected to further illustrate the great practical value of CNFs network material in biologically hybridized electrochemical systems and provide an ingenious route to construct a robust electrochemical electrode for biosensing. 


\section{Materials and Methods}

\subsection{Chemicals and Reagents}

$\mathrm{AFB}_{1}$ (purity $\left.\geq 98.0 \%\right)$, aflatoxin $\mathrm{B}_{2}\left(\mathrm{AFB}_{2}\right.$, purity $\left.\geq 98.0 \%\right)$, aflatoxin $\mathrm{G}_{1}\left(\mathrm{AFG}_{1}\right.$, purity $\geq 98.0 \%$ ), aflatoxin $\mathrm{G}_{2}\left(\mathrm{AFG}_{2}\right.$, purity $\geq 98.0 \%$ ), ochratoxin $\mathrm{A}$ (OTA, purity $\geq 98.0 \%$ ), deoxynivalenol ( $\mathrm{DON}$, purity $\geq 98.0 \%$ ), zearalenone (ZEN, purity $\geq 98.0 \%$ ), bovine serum albumin (BSA, purity $\geq 98.0 \%$ ), chloroauric acid $\left(\mathrm{HAuCl}_{4} \cdot 3 \mathrm{H}_{2} \mathrm{O}\right.$, purity $\geq 99.9 \%$ ), and PEI (average M.W. 2500, purity $\geq 99.0 \%$ ) were purchased from Sigma-Aldrich (Shanghai) Trading Co., Ltd. (Shanghai, China). Monoclonal antibody (Ab, $1 \mathrm{mg} \mathrm{mL}^{-1}$, purified by protein $G$ resin) against $A_{F B}$ was provided by Dr. D. Wang. [43] The multiwalled CNTs (diameter: 20-40 nm, length: 1-2 $\mu \mathrm{m}$, purity: > 95\%) were purchased from Shenzhen Nanotech Port Co. Ltd. (Shenzhen, China), and were purified according to our previous work [44]. The hydrogel pellicles of bacterial celluloses were provided by Ms. C.Y. Zhong (Hainan Yeguo Foods Co., Ltd. Haikou, China). Wheat samples were bought from a local supermarket. All other inorganic chemicals and organic solvents were analytical reagents grade, purchased from China National Pharmaceutical Industry Co., Ltd. (Beijing, China), and used without further purification. All aqueous solutions and buffers were prepared with deionized water (resistance of $18.2 \mathrm{M} \Omega \mathrm{cm}^{-1}$ ) produced from a Millipore $\mathrm{Q}$ water purification system.

\subsection{Apparatus}

Cyclic voltammetry (CV) and differential pulse voltammetry (DPV) were performed on a CHI 760E electrochemical workstation (Chenhua Instrument Shanghai Co., Ltd. Shanghai, China). A typical three-electrode system consisting of an $\mathrm{Ag} / \mathrm{AgCl}$ reference electrode, a Pt wire counter electrode and a modified glassy carbon electrode (GCE, $\Phi=3 \mathrm{~mm}$ ) as working electrode, was used for all electrochemical measurements. The morphologies of prepared nanomaterials were observed on a JSM-7800F field emission scanning electron microscope (FESEM, JEOL, Tokyo, Japan) and a JEM-2100F transmission electron microscope (TEM, JEOL, Tokyo, Japan).

\subsection{Preparation of Au@PEI@CNFs Nanocomposites}

The CNF aerogels were derived from hydrogel pellicles of bacterial celluloses through vacuum freeze drying followed by carbonization at $1000{ }^{\circ} \mathrm{C}$ under a flowing argon atmosphere, according to our previous report [40]. The hybridized nanomaterials were synthesized by in-situ formation of AuNPs on PEI-functionalized CNFs under a mild heating condition, where the PEI not only acts as a dispersing agent but also a reducing agent for reduction of $\mathrm{HAuCl}_{4}$, as demonstrated by Hu et al. [42]. In a typical synthesis, $2.5 \mathrm{mg}$ CNFs were dispersed in $5 \mathrm{~mL}$ of $0.3 \mathrm{wt} \%$ PEI aqueous solution with the help of ultrasonic processing for $2 \mathrm{~h}$. After centrifugal collection, the precipitates of PEI-modified CNFs (PEI@CNFs) were resuspended in $5 \mathrm{~mL}$ of $1 \mathrm{mM} \mathrm{HAuCl}_{4}$ solution followed by magnetic stirring for $30 \mathrm{~min}$ at ambient temperature $\left(25 \pm 2{ }^{\circ} \mathrm{C}\right)$. The suspension was kept at $60{ }^{\circ} \mathrm{C}$ under static condition for $1 \mathrm{~h}$, leading to the formation of $\mathrm{Au} / \mathrm{PEI} / \mathrm{CNFs}$ hybrids accompanied by the color change from yellowish to black-purple. The product was collected by centrifugation at $10,000 \mathrm{~g}$ for $10 \mathrm{~min}$ at $10{ }^{\circ} \mathrm{C}$ and washed with deionized water until the supernatant became colorless after centrifugation. Finally, the precipitates of Au@PEI@CNFs nanocomposites were dried at $60{ }^{\circ} \mathrm{C}$ in a vacuum dryer. The Au@PEI@CNTs used for comparison were synthesized by the same approach above, except that the CNTs replaced the CNFs.

\subsection{Fabrication of Amperometric Immunosensor}

The stepwise schematic illustration of the fabrication procedure for the $\mathrm{AFB}_{1} \mathrm{im}$ munosensor is illustrated in Figure 1. The GCE was successively polished with alumina slurry of 1.0, 0.3 and $0.05 \mu \mathrm{m}$, followed by sonication (frequency of $20 \mathrm{kHz}$ ) for $30 \mathrm{~s}$ at $25 \pm 2{ }^{\circ} \mathrm{C}$ in deionized water and ethanol in turn, and then dried at room temperature $\left(25 \pm 2{ }^{\circ} \mathrm{C}\right)$. A sample of $10 \mu \mathrm{L}$ of the $\mathrm{Au} / \mathrm{PEI} / \mathrm{CNFs}$ suspension $\left(1 \mathrm{mg} \mathrm{mL}^{-1}\right)$ was dropped 
on the electrode surface, followed by evaporation of the solvent in air. Afterwards, $6 \mu \mathrm{L}$ of anti-AFB 1 antibody in 0.01 $\mathrm{M}$ phosphate-buffered saline (PBS, $\mathrm{pH} 7.0$ ) was immobilized onto the modified electrode through electrostatic interaction during an incubation process at $37{ }^{\circ} \mathrm{C}$ under a moisturizing condition. After washing with PBS, the electrode was kept in a $3 \mathrm{wt} \%$ BSA solution for $1 \mathrm{~h}$ to eliminate nonspecific binding sites and then rinsed. Then $6 \mu \mathrm{L}$ of $\mathrm{AFB}_{1}$ solution with a series of concentrations $(0.05,0.2,1,2,5,10,15,20$ and $25 \mathrm{ng} \mathrm{mL}^{-1}$ ) was dropped onto the electrode surface for specific combination for a certain amount of time. After being rinsed with PBS containing 0.05\% Tween-20 and dried, the assembled immunosensor was stored at $4{ }^{\circ} \mathrm{C}$ for subsequent use.

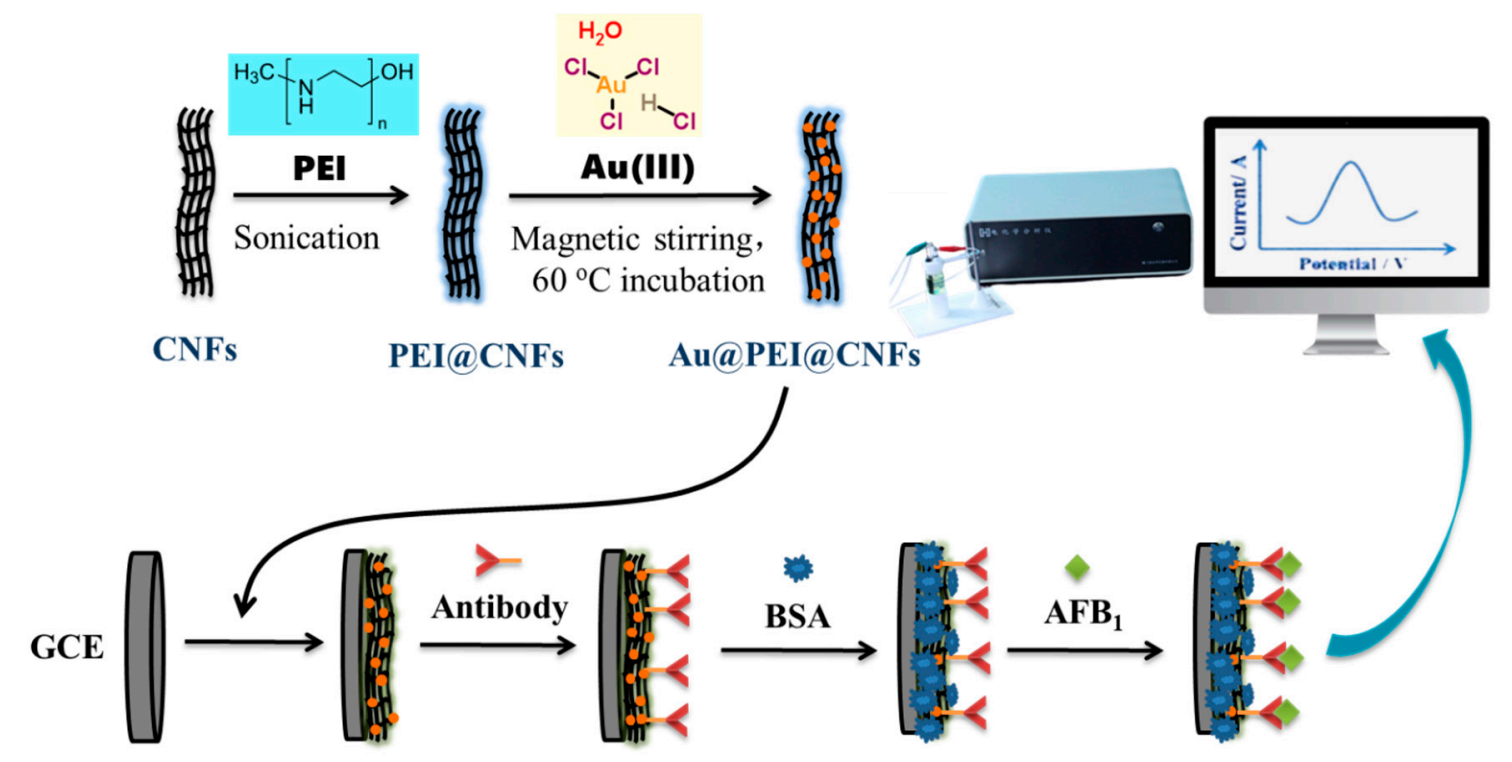

Figure 1. Stepwise illustration of fabrication procedure of the amperometric immunosensor based on interconnected carbon nanofibers (CNFs) network decorated with AuNPs (Au@PEI@CNFs nanocomposites).

\subsection{Sample Preparation}

Noncontaminated wheat samples obtained from a local market, which were verified by a commercial ELISA kit with a limit of detection (LOD) of $0.1 \mu \mathrm{g} \mathrm{kg}^{-1}$ (Huaan Magnech Bio-tech Co., Ltd., Beijing, China), were ground. Aliquots (5 g) of pulverized samples were extracted with $25 \mathrm{~mL}$ methanol-water $(70: 30, v / v)$ for $30 \mathrm{~min}$ on a vortex shaker. After centrifugation at $10,000 \mathrm{~g}$ for $10 \mathrm{~min}$ at $10^{\circ} \mathrm{C}$, the supernatant was filtered through a $0.45 \mu \mathrm{m}$ filter membrane (Jinteng Experimental Equipment Co., Ltd., Tianjin, China) and then stored at $-20^{\circ} \mathrm{C}$ for further assay. The extracting solution was diluted five-fold with 0.01 M PBS buffer before $\mathrm{AFB}_{1}$ detection, which means a total dilution of 25 -fold. In order to evaluate accuracy and precision of the developed immunosensor, three spiked wheat samples with $\mathrm{AFB}_{1}$ concentrations of 5,25 and $100 \mu \mathrm{g} \mathrm{kg}^{-1}$ were prepared, followed by being extracted according to above approach for determination of $\mathrm{AFB}_{1}$.

\subsection{Electrochemical Measurements}

The modified electrodes were characterized using $\mathrm{CV}$ at a scan rate of $30 \mathrm{mV} \mathrm{s}$ by scanning the potential from -0.2 to $0.6 \mathrm{~V}$, which was performed in a deaerated PBS solution containing $5 \mathrm{mM} \mathrm{K}_{3}\left[\mathrm{Fe}(\mathrm{CN})_{6}\right] / \mathrm{K}_{4}\left[\mathrm{Fe}(\mathrm{CN})_{6}\right]$ as a redox probe. DPV for $\mathrm{AFB}_{1}$ determination was recorded with a potential ranging from -0.2 to $0.6 \mathrm{~V}$, pulse amplitude of $50 \mathrm{mV}$, pulse width of $0.05 \mathrm{~s}$ and pulse period of $0.5 \mathrm{~s}$. DPV peak current change $(\Delta \mathrm{Ip})$ was calculated by using the equation of $\Delta \mathrm{I}=\mathrm{I}_{0}-\mathrm{I}_{\mathrm{i}}$, where $\mathrm{I}_{0}$ was the current response obtained in blank solution and $\mathrm{I}_{\mathrm{i}}$ was the current response obtained in the case of $\mathrm{AFB}_{1}$ concentrations. 


\section{Results and Discussion}

\subsection{Characterization of Nanocomposites}

Surface morphologies of the as-prepared Au@PEI@CNFs and Au@PET@CNTs nanocomposites were observed by FESEM. The Au@PEI@CNFs (Figure 2A,B) showed an interconnected network architecture consisting of carbon nanofibers with a diameter range from 20 to $50 \mathrm{~nm}$. In spite of undergoing the chemical modification process, the 3-D structure of CNFs [40] remained intact, indicating its plasticity and toughness. On the contrary, the Au@PET@CNTs (Figure 2C) exhibited a dense structure due to aggregation. Intuitively, this stuffed structure would be not conducive to diffusion of electrolyte and interfacial electrochemical reaction compared to the 3-D reticular porous architecture of Au@PEI@CNFs. AuNPs with a size range from several to dozens of nanometers were, as expected, grafted uniformly on the surfaces of both CNFs and CNTs because of the dispersion effect and reduction action of the PEI coating. The TEM image (Figure 2D) of Au@PEI@CNFs further demonstrated the cross-linked structure of CNFs and the depositions of AuNPs. In addition, some small nanocrystals were also observed on the fibers of CNFs in the high-resolution TEM image (Figure 2E), which were deemed to be nucleation sites of AuNPs. Subsequently, the as-prepared powdered materials were dropped onto a GCE surface for electrochemical characterization. As shown in Figure 3, the CV curves of all tested electrode materials showed a couple of well-defined and reversible redox peaks originating from the redox reaction of $\left[\mathrm{Fe}(\mathrm{CN})_{6}\right]^{3-/ 4-}$ on the electrode interfaces, and an increased peak-current in varying degrees in comparison to the bare GCE. Moreover, according to the peak area of the CV curve, the estimated electrochemical active area of Au@PEI@CNFs was approximately 1.23-fold that of Au@PEI@CNTs and of CNFs was 1.27-fold, which could be mainly attributed to the much larger surface area and more accessible pores of CNFs than the CNTs [40]. Taken together, the CNFs could be demonstrated to be an applicable substrate for constructing functional nanomaterials with efficient 3-D reticular porous structures and promising electrocatalytic performances.

\subsection{Immunosensor Fabrication}

The fabrication process of the immunosensor is another key issue for the development of sensing platform, which was monitored using a CV technique after each step [45]. As shown in Figure 4 (line a), there were well-defined and reversible $\left[\mathrm{Fe}(\mathrm{CN})_{6}\right]^{3-/ 4-}$ redox peaks for the bare GCE. The peak-current of the Au@PEI@CNFs nanocomposites modified GCE as shown in Figure 4 (line b) increased remarkably, which could be probably attributed to the high conductivity and large electrochemical active area of the Au@PEI@CNFs nanocomposites. While the peak-current decreased apparently after being modified with anti-AFB 1 antibody, as shown in Figure 4 (line c). Such attenuation of peak-current indicated that the anti-AFB 1 antibody was successfully immobilized on the electrode surface because the nonconductive molecule can retard the interfacial electron transfer between the redox probe of $\left[\mathrm{Fe}(\mathrm{CN})_{6}\right]^{3-/ 4-}$ and the electrode surface. Then, the as-prepared electrode was immersed in BSA solution to block any possible remaining nonspecific active sites, which resulted in a further decrease of peak-current for the same reason. More importantly, the peak-current decreased again after the $\mathrm{AFB}_{1}$ was dropped onto the electrode, which indicated the successful capture of $\mathrm{AFB}_{1}$ and the formation of an immunocomplex after the specific recognition between antigen and antibody. Such a produced immunocomplex layer greatly hindered interfacial electron transfer. Therefore, the fabricated GCE/Au@PEI@CNFs/Ab/BSA/AFB 1 immunosensor can be used for the detection of $\mathrm{AFB}_{1}$. 

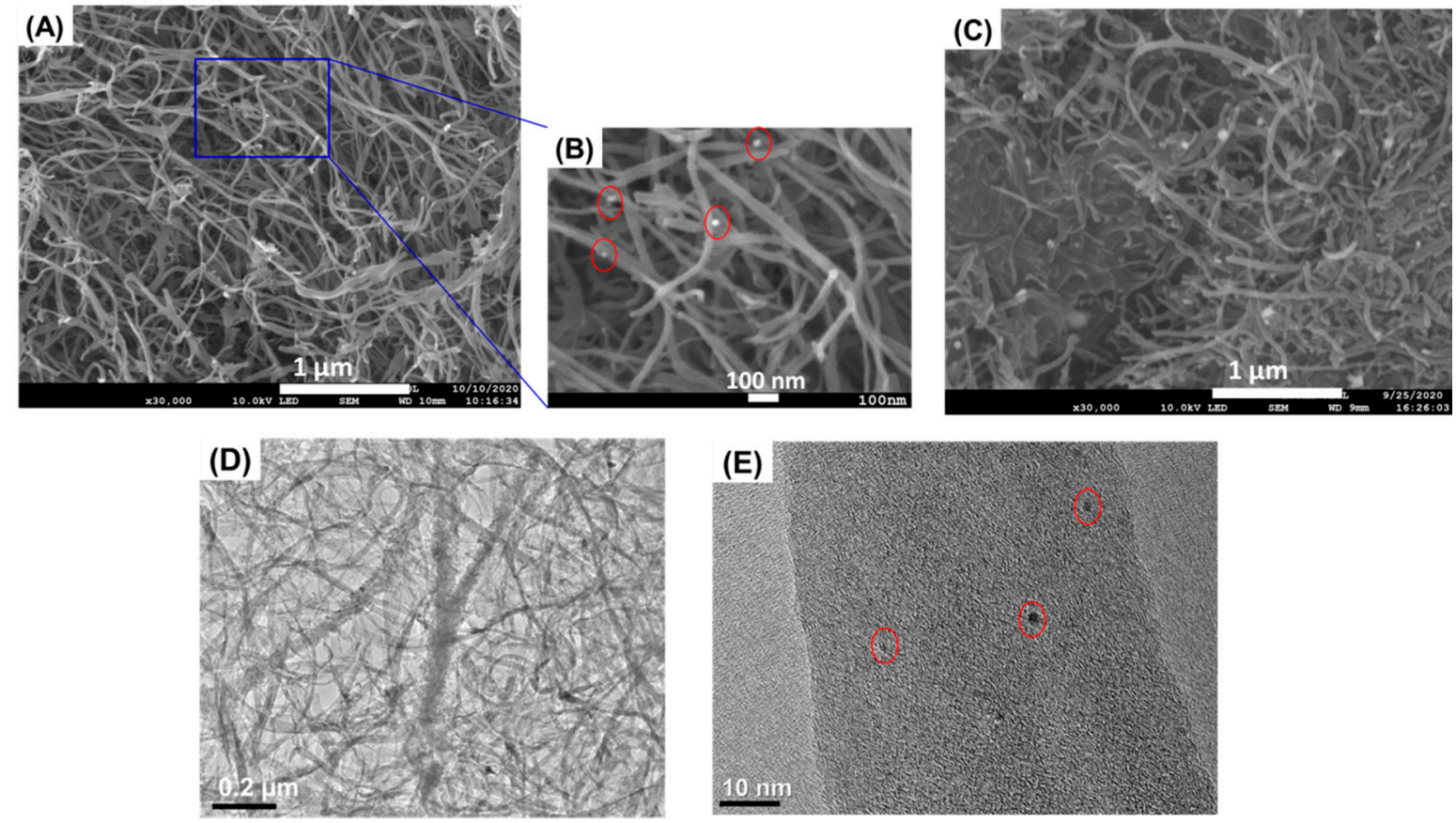

Figure 2. Morphological characterization of the prepared nanocomposites. SEM images of Au@PEI@CNFs (A,B) and Au@PEI@CNTs (C), TEM images of Au@PEI@CNFs (D,E).

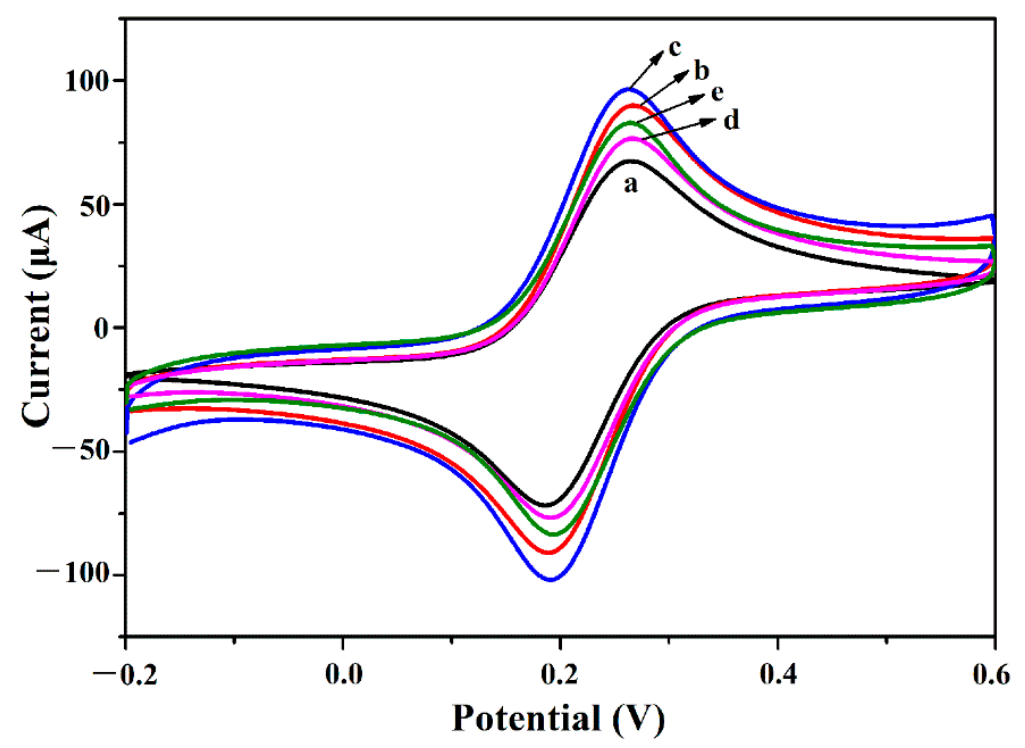

Figure 3. Electrochemical characterization of the prepared nanocomposites. CV graphs of (line a) bare glass carbon electrode (GCE), (line b) GCE/CNFs, (line c) GCE/Au@PEI@CNFs, (line d) GCE/carbon nanotubes (CNTs) and (line e) GCE/Au@PEI@CNTs, respectively. CVs were recorded at a scan rate of $30 \mathrm{mV} \mathrm{s}^{-1}$ in PBS solution containing $5 \mathrm{mM} \mathrm{K}_{3}\left[\mathrm{Fe}(\mathrm{CN})_{6}\right] / \mathrm{K}_{4}\left[\mathrm{Fe}(\mathrm{CN})_{6}\right]$. 


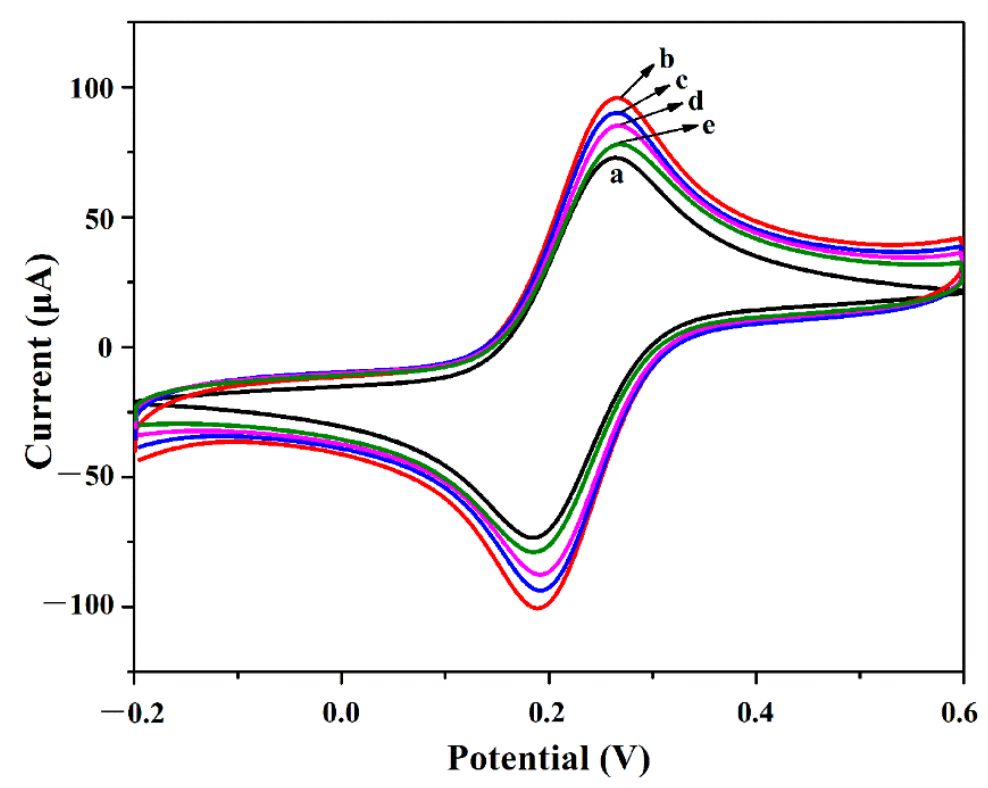

Figure 4. Electrochemical monitor of the immunosensor fabrication. CV curves of (line a) GCE, (line b) GCE/Au@PEI@CNFs, (line c) GCE/Au@PEI@CNFs/Ab, (line d) GCE/Au@PEI@CNFs / Ab/BSA and (line e) GCE/Au@PEI@CNFs/Ab/BSA/AFB 1 in PBS solution (pH 7.4) containing 5 mM $\mathrm{K}_{3}\left[\mathrm{Fe}(\mathrm{CN})_{6}\right] / \mathrm{K}_{4}\left[\mathrm{Fe}(\mathrm{CN})_{6}\right]$. Scan rate: $30 \mathrm{mV} \mathrm{s}^{-1}$.

\subsection{Optimization of Determination Conditions}

The sensitivity of an immunosensor relies, o a large extent, on the concentration of antibody and the immunoreaction time [46,47]. The effects of these two influential factors were examined by means of DPV, and the peak-current decrease $(\Delta \mathrm{Ip})$ was applied as the indicator to evaluate the optimum condition for sensitively detecting the target analyte of $5 \mathrm{ng} \mathrm{mL} \mathrm{m}^{-1} \mathrm{AFB}_{1}$. As shown in Figure $5 \mathrm{~A}$, the $\Delta \mathrm{Ip}$ increased gradually with increasing concentration of antibody (too low an amount of antibody could not recognize the target analyte effectively), and then tended to be stable at $125 \mu \mathrm{g} \mathrm{mL} \mathrm{m}^{-1}$. In consequence, an antibody concentration of $125 \mu \mathrm{g} \mathrm{mL}^{-1}$ was selected for the preparation of the proposed immunosensor. Likewise, the $\Delta \mathrm{Ip}$ increased gradually with increasing immunoreaction time from 10 to $45 \mathrm{~min}$ and decreased slightly with a further increase in time (Figure 5B). Therefore, an immunoreaction time of $45 \mathrm{~min}$ was adopted as the optimal antigen/antibody binding time throughout the subsequent experiment.

(A)

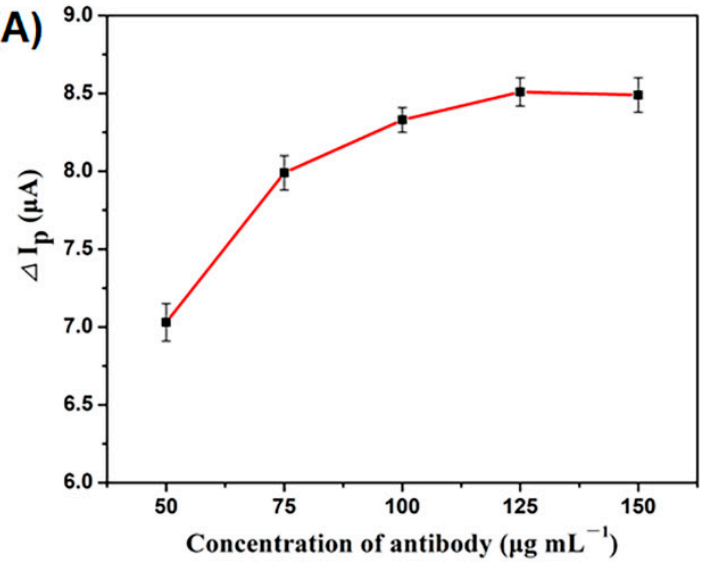

(B)

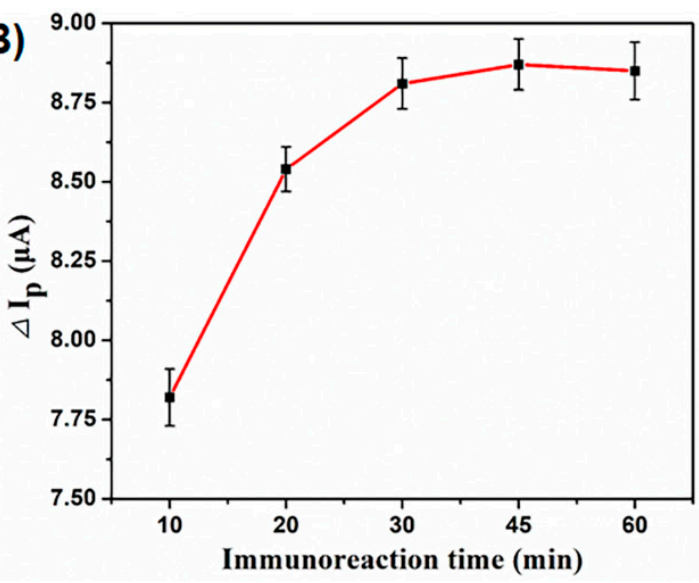

Figure 5. Effects of the antibody concentration (A) and immunoreaction time (B) on the detection sensitivity of the proposed immunosensor, error bar $=\operatorname{RSD}(n=3)$. 


\subsection{Analytical Performance of the Immunosensor}

The analytical performance of the proposed immunosensor was carried out by determination of different $\mathrm{AFB}_{1}$ concentrations by means of DPV under the optimized conditions. Firstly, the nonspecific adsorption of $\mathrm{AFB}_{1}$ on $\mathrm{Au} @ \mathrm{PEI} @ \mathrm{CNFs}$-based immunosensor was evaluated through the decrease in peak-current when in the absence of anti-AFB 1 antibody. Only a $0.45 \mu \mathrm{A}$ of attenuation was detected after the addition of $5 \mathrm{ng} \mathrm{mL} \mathrm{m}^{-1} \mathrm{AFB}_{1}$, which was about $5 \%$ of that when in the presence of anti-AFB1 antibody. This indicated that the decrease in peak-current for the Au@PEI@CNFs-based immunosensor was almost entirely attributed to the specific capture of $\mathrm{AFB}_{1}$ by the antibody and the nonspecific adsorption had a negligible impact on the analytical capacity. Apparently, as shown in Figure $6 \mathrm{~A}$, the peak-current (Ip) decreased gradually with increasing concentration of $\mathrm{AFB}_{1}$, which indicated the workable capacity of quantitative analysis for the immunosensor. The relationship of the Ip and the concentration of $\mathrm{AFB}_{1}$ was well fitted into a simple linear regression in a range from 0.05 to $25 \mathrm{ng} \mathrm{mL}^{-1}$ (Figure 6B). For the Au@PEI@CNFs functionalized immunosensor, the linear regression equation of the calibration curve was Ip $(\mu \mathrm{A})$ $=57.967-1.239$ Con. $\left(\mathrm{ng} \mathrm{mL}{ }^{-1}\right)$ with a determination coefficient $\left(R^{2}\right)$ of 0.995 (Con. is the abbreviation for concentration). The LOD was estimated to be $0.027 \mathrm{ng} \mathrm{mL}^{-1}(\mathrm{~S} / \mathrm{N}=3, \mathrm{n}$ = 6), much lower than that for the Au@PEI@CNTs-based immunosensor $\left(0.093 \mathrm{ng} \mathrm{mL}^{-1}\right)$. Apparently, the low LOD of developed immunosensor based on Au@PEI@CNTs was enough to meet the limit standards of $\mathrm{AFB}_{1}$ prescribed by China and European Commission in the majority of agricultural and food products ( 5 and $2 \mu \mathrm{g} \mathrm{kg}^{-1}$, respectively) and even infant food ( 0.5 and $0.1 \mu \mathrm{g} \mathrm{kg}{ }^{-1}$, respectively). Given the consistent immunosensor fabrication approach and analytic conditions, the superior detection sensitivity for the $\mathrm{Au} @ \mathrm{PEI} @ \mathrm{CNF}$ electrode material could be due to its particular 3-D reticular porous structure and large electrochemical active area. In addition, the dynamic range and LOD of this proposed immunosensor were comparable to most previous reports on the amperometric immunosensors (Table 1).

The reproducibility, storage stability and selectivity of the immunosensor were investigated subsequently. A series of six immunosensors based on Au@PEI@CNFs nanocomposites were prepared in the same way to detect $\mathrm{AFB}_{1}\left(5 \mathrm{ng} \mathrm{mL}^{-1}\right)$. The relative standard deviation (RSD) of the measurements for the six immunosensors was $4.66 \%$, which suggested that the reproducibility of the proposed immunosensor for $\mathrm{AFB}_{1}$ detection was acceptable. In order to evaluate storage stability, three immunosensors were fabricated and stored at 4 ${ }^{\circ} \mathrm{C}$ under refrigeration. These immunosensors were applied for the determination of $\mathrm{AFB}_{1}$, and the electrochemical responses of them were recorded every three days (Figure 6C). After three and nine days, respectively, 97.25 and $94.39 \%$ of initial $\Delta$ Ip remained. Nevertheless, after twelve days less than $90 \%$ of the initial $\Delta \mathrm{Ip}$ was observed. Taken together, the stability of the immunosensor was richly satisfactory within one week, which could result from good stability of both antibody and Au@PEI@CNFs nanocomposites, as well as their form immobilization on the GCE surface. Further, the cocontamination of other mycotoxins (including the homologues of $\mathrm{AFB}_{1}$ as well as DON, OTA and ZEN) often occurs in wheats and their products. [48] Therefore, the cross-reactivity of the developed immunosensor towards these mycotoxins was investigated (Figure 6D). Expectedly, the cross-reactivities for all tested mycotoxins, except for the homologues of $\mathrm{AFB}_{1}$ (i.e., $\mathrm{AFB}_{2}, \mathrm{AFG}_{1}$ and $\mathrm{AFG}_{2}$ ), were less than $5 \%$ because the specificity of an immunosensor is primarily dependent on that of the used antibody, while the cross-reactivities for $\mathrm{AFB}_{2}, \mathrm{AFG}_{1}$ and $\mathrm{AFG}_{2}$ were 44.64 , 14.32 and $18.38 \%$, respectively. This result indicated that the developed immunosensors was suitable to detect $A F B_{1}$ rather than the total aflatoxins, which is mainly dependent on the affinity and specificity of the monoclonal antibody used. 

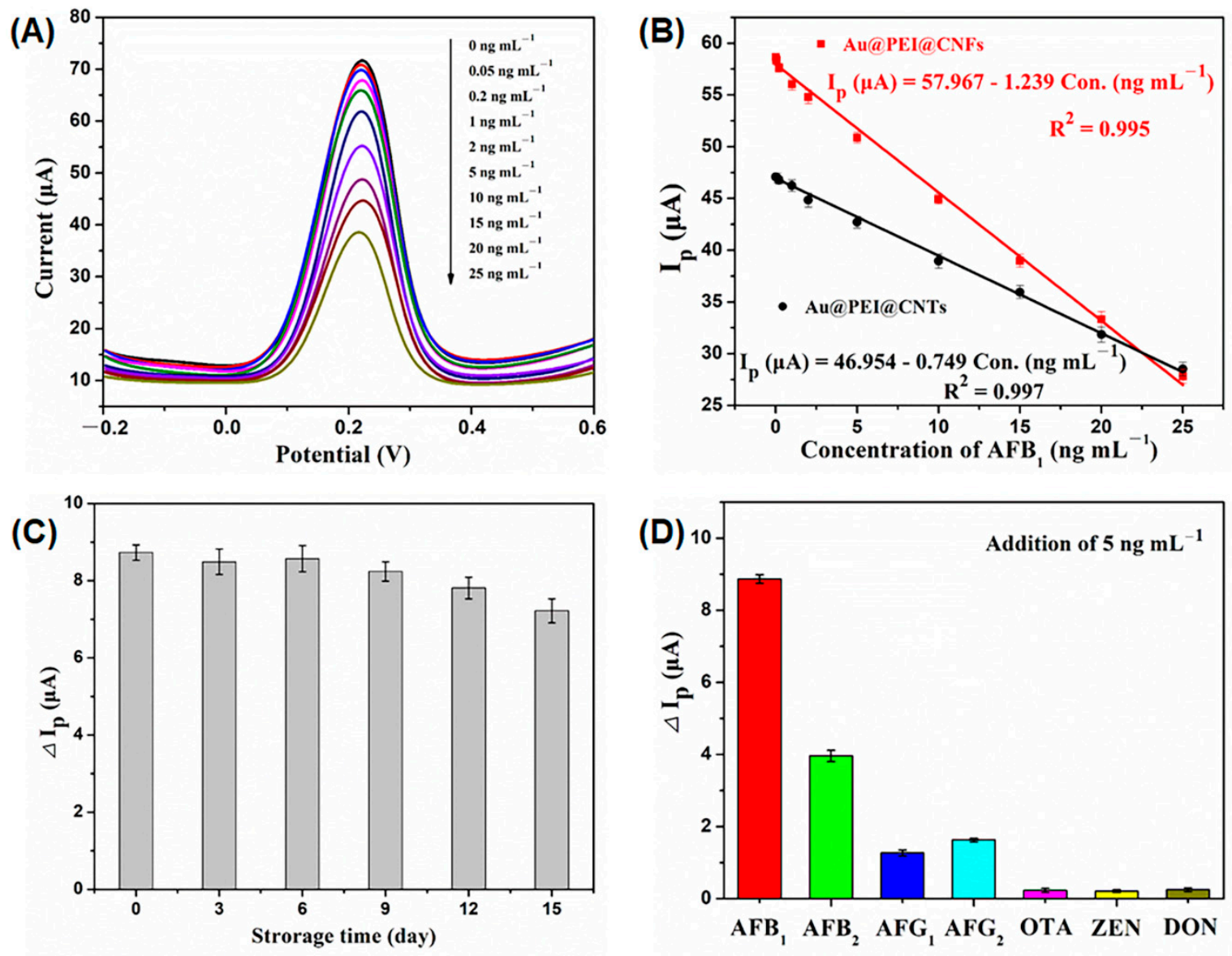

Figure 6. Analytical performance of the proposed immunosensor. (A) Differential pulse voltammetry (DPV) responses of the Au@PEI@CNFs-based immunosensor to different concentrations of AFB 1 . (B) Calibration curves of immunosensors to different concentrations of $\mathrm{AFB}_{1}$, error bar $=\operatorname{RSD}(n=6)$. (C) Peak-current change $(\Delta \mathrm{Ip})$ responses of immunosensors to different storage time, error bar $=\operatorname{RSD}(n=3)$. (D) Peak-current change $(\Delta \mathrm{Ip})$ responses of immunosensors to different mycotoxins $\left(5 \mathrm{ng} \mathrm{mL}^{-1}\right)$, error bar $=\operatorname{RSD}(\mathrm{n}=3)$.

Table 1. Comparison of the proposed immunosensor and other amperometric sensors.

\begin{tabular}{cccc}
\hline Modified Electrode & Linearity $\left(\mathbf{n g} \mathbf{~ m L}^{-\mathbf{1}}\right)$ & LOD $\left.\mathbf{( n g} \mathbf{~ m L}^{-\mathbf{1}}\right)$ & Reference \\
\hline Au@PEI@CNFs/GCE & $0.05-25$ & 0.027 & This work \\
Au@PEI@CNTs/GCE & $0.05-25$ & 0.093 & This work \\
CNTs/PDDA/Pd- & $0.05-25$ & 0.03 & {$[34]$} \\
Au/GCE & & & \\
AuNPs/PEDOT- & $0.5-60$ & 0.109 & {$[49]$} \\
GO/GCE & $0.2-30$ & 0.12 & {$[50]$} \\
CHI-AuNPs/GCE & $0.1-30$ & 0.06 & {$[51]$} \\
CHI-AuNPs/GCE & $0.05-25$ & 0.034 & {$[52]$} \\
Au/PANI/GN/GCE & $0.6-2.4$ & 0.07 & {$[53]$} \\
PTH/AuNP/GCE & $0.1-12$ & 0.050 & {$[54]$} \\
Au/TiO2/RTIL/Nafion/GCE & $1-225$ & 0.5 & {$[55]$} \\
MWCNTs/AFO & $0.04-8$ & 0.019 & {$[20]$} \\
PoPD/3DNEEs & & &
\end{tabular}

\subsection{Analysis of Wheat Samples}

As indicated above, the proposed label-free amperometric immunosensor showed great application potential in $\mathrm{AFB}_{1}$ determination. For the sake of proving the feasibility for real sample analysis, the as-prepared immunosensors were used to detect the blank wheat samples spiked with standard $\mathrm{AFB}_{1}$ at different concentrations $\left(2,25\right.$, and $\left.200 \mu \mathrm{g} \mathrm{kg}^{-1}\right)$. The extracts of the spiked samples were diluted five-fold before undergoing electrochemical 
analysis to mitigate sample matrix interference as much as possible. The recovery values of intra-assay and interassay lay in the range of $89.06-105.80 \%$ and $85.94-111.60 \%$, respectively (Table 2). Correspondingly, the RSD values were in the range of $7.38-11.35 \%$ and $10.04-$ $13.80 \%$, respectively. Apparently, all test values of both recovery and RSD were within the corresponding reference ranges for a quantitative method prescribed by European Commission (Decision No. 2002/657/EC) [56], except for the inter-assay recovery of $111.60 \%$ at the low spiked concentration $\left(5 \mu \mathrm{g} \mathrm{kg}{ }^{-1}\right)$, slightly exceeding the recommended maximum reference value of $110 \%$. There was a tendency of the recovery value to decrease as the spiked concentration of $\mathrm{AFB}_{1}$ increased, which might be due to the incomplete extraction at the high concentration, but this would not affect the immunosensor used to determine whether a wheat sample is contaminated or not. Overall, the results suggested that the developed immunosensor could be applied to detect $\mathrm{AFB}_{1}$ in real samples with acceptable accuracy and precision.

Table 2. Recovery analysis of $\mathrm{AFB}_{1}$ from spiked wheat samples by the proposed immunosensor.

\begin{tabular}{|c|c|c|c|}
\hline $\begin{array}{l}\text { Spiked Concentration } \\
\left(\mu \mathrm{g} \mathrm{kg}^{-1}\right)\end{array}$ & $\begin{array}{c}\text { Detected Concentration } \\
\left(\text { Mean } \pm \mathrm{SD}, \mu \mathrm{g} \mathrm{kg}{ }^{-1}\right)\end{array}$ & $\begin{array}{l}\text { Recovery } \\
(\%)\end{array}$ & $\begin{array}{c}\text { RSD } \\
(\%)\end{array}$ \\
\hline \multicolumn{4}{|c|}{ Intra-assay $(\mathrm{n}=6)$} \\
\hline 5 & $5.29 \pm 0.61$ & 105.80 & 11.35 \\
\hline 25 & $23.58 \pm 2.16$ & 94.32 & 9.16 \\
\hline 200 & $178.13 \pm 13.15$ & 89.06 & 7.38 \\
\hline \multicolumn{4}{|c|}{ Inter-assay $(n=6)$} \\
\hline 5 & $5.58 \pm 0.77$ & 111.60 & 13.80 \\
\hline 25 & $24.43 \pm 3.02$ & 97.72 & 12.36 \\
\hline 200 & $171.88 \pm 17.26$ & 85.94 & 10.04 \\
\hline
\end{tabular}

\section{Conclusions}

In this work, a CNFs network was successfully adopted to a 3-D carbonaceous substrate for constructing functional nanocomposites to improve the performance of an immunosensor. On account of its unique interconnected structure with hierarchical pores and large surface area, the CNFs network showed superior electrochemical features compared to common CNTs when combined with AuNPs. In consequence, the Au@PEI@CNFs-based immunosensor achieved a wide dynamic range from 0.05 to $25 \mathrm{ng} \mathrm{mL}^{-1}$ with a low LOD of $0.027 \mathrm{ng} \mathrm{mL}{ }^{-1}$, which was three-fold more sensitive than the Au@PEI@CNTs-based one. The immunosensor also exhibited excellent stability and selectivity, and good applicability in analysis of real wheat samples. Thus, the CNFs network has been proved substantially to be a promising functional nanomaterial for construction of biosensors based on amperometric analysis. In addition, its feasible application in electrochemical impedance spectroscopy-based biosensors would be another interesting research topic in view of a possible higher detection sensitivity, requiring a further specific study.

Author Contributions: Conceptualization, W.W. and L.Z.; methodology, Y.H. and L.Z.; software, F.Z.; validation, L.Z.; formal analysis, F.Z.; investigation, Y.H. and J.G.; resources, W.W. and L.Z.; data curation, Y.H. and F.Z.; writing-original draft preparation, Y.H.; writing — review and editing, W.W. and L.Z.; visualization, F.Z. and J.G.; supervision, L.Z.; project administration, W.W. and L.Z.; funding acquisition, W.W. and L.Z. All authors have read and agreed to the published version of the manuscript.

Funding: This research was funded by Open Project of State Key Laboratory for Managing Biotic and Chemical Threats to the Quality and Safety of Agro-products, grant number 2010DS700124KF1904; Key Project of Youth Science Foundation of Jiangxi Province, grant number 20202ACB215001; and Youth Project of "Double Thousand-Plan" of Jiangxi Province.

Institutional Review Board Statement: Not applicable.

Informed Consent Statement: Not applicable.

Data Availability Statement: Not applicable. 
Conflicts of Interest: The authors declare no conflict of interest.

\section{References}

1. Marin, S.; Ramos, A.; Cano-Sancho, G.; Sanchis, V. Mycotoxins: Occurrence, toxicology, and exposure assessment. Food Chem. Toxicol. 2013, 60, 218-237. [CrossRef]

2. Bedard, L.L.; Massey, T.E. Aflatoxin B1-induced DNA damage and its repair. Cancer Lett. 2006, 241, 174-183. [CrossRef]

3. Reddy, K.; Salleh, B.; Saad, B.; Abbas, H.; Abel, C.; Shier, W. An overview of mycotoxin contamination in foods and its implications for human health. Toxin Rev. 2010, 29, 3-26. [CrossRef]

4. Yu, Y.; Shi, J.; Xie, B.; He, Y.; Qin, Y.; Wang, D.; Shi, H.; Ke, Y.; Sun, Q. Detoxification of aflatoxin B1 in corn by chlorine dioxide gas. Food Chem. 2020, 328, 127121. [CrossRef] [PubMed]

5. National Health and Family Planning Commission of China; State Food and Drug Administration of China. Maximum Levels of Mycotoxins in Foods (GB 2761-2017); China Standard Press: Beijing, China, 2017.

6. European Commission. Commission Regulation (EC) No 1881/2006 of 19 December 2006. Setting maximum levels for certain contaminants in foodstuffs. Off. J. Eur. Union 2006, 364, 5-24.

7. Zhang, B.; Yu, L.; Liu, Z.; Lu, H.; Fu, X.; Du, D. Rapid determination of aflatoxin B1 by an automated immunomagnetic bead purification sample pretreatment method combined with high-performance liquid chromatography. J. Sep. Sci. 2020, 43, 3509-3519. [CrossRef] [PubMed]

8. Huertas-Pérez, J.F.; Arroyo-Manzanares, N.; Hitzler, D.; Castro-Guerrero, F.G.; Gámiz-Gracia, L.; García-Campaña, A.M. Simple determination of aflatoxins in rice by ultra-high performance liquid chromatography coupled to chemical post-column derivatization and fluorescence detection. Food Chem. 2018, 245, 189-195. [CrossRef] [PubMed]

9. Muscarella, M.; Iammarino, M.; Nardiello, D.; Magro, S.L.; Palermo, C.; Centonze, D.; Palermo, D. Validation of a confirmatory analytical method for the determination of aflatoxins B1, B2, G1and G2in foods and feed materials by HPLC with on-line photochemical derivatization and fluorescence detection. Food Addit. Contam. Part A 2009, 26, 1402-1410. [CrossRef]

10. Zitomer, N.; Rybak, M.E.; Li, Z.; Walters, M.J.; Holman, M.R. Determination of Aflatoxin B1in Smokeless Tobacco Products by Use of UHPLC-MS/MS. J. Agric. Food Chem. 2015, 63, 9131-9138. [CrossRef]

11. Campone, L.; Rizzo, S.; Piccinelli, A.L.; Celano, R.; Pagano, I.; Russo, M.; Labra, M.; Rastrelli, L. Determination of mycotoxins in beer by multi heart-cutting two-dimensional liquid chromatography tandem mass spectrometry method. Food Chem. 2020, 318, 126496. [CrossRef]

12. Wang, X.; Li, P.; Yang, Y.; Zhang, W.; Zhang, Q.; Fan, S.; Yu, L.; Wang, L.; Chen, X.; Li, Y.; et al. Determination of aflatoxins in cereals and oils by liquid chromatography-triple quadrupole tandem mass spectrometry. Chin. J. Chromatogr. 2011, $29,517-522$. [CrossRef] [PubMed]

13. Pan, D.; Li, G.; Hu, H.; Xue, H.; Zhang, M.; Zhu, M.; Gong, X.; Kennis, J.T.M.; Wan, Y.; Shen, Y. Direct Immunoassay for Facile and Sensitive Detection of Small Molecule Aflatoxin B1 based on Nanobody. Chem. A Eur. J. 2018, 24, 9869-9876. [CrossRef] [PubMed]

14. Yang, L.; Ding, H.; Gu, Z.; Zhao, J.; Chen, H.; Tian, F.; Chen, Y.Q.; Zhang, H.; Chen, W. Selection of Single Chain Fragment Variables with Direct Coating of Aflatoxin B1to Enzyme-Linked Immunosorbent Assay Plates. J. Agric. Food Chem. 2009, 57, 8927-8932. [CrossRef] [PubMed]

15. Sojinrin, T.; Liu, K.; Wang, K.; Cui, D.; Byrne, H.J.; Curtin, J.; Tian, F. Developing Gold Nanoparticles-Conjugated Aflatoxin B1 Antifungal Strips. Int. J. Mol. Sci. 2019, 20, 6260. [CrossRef]

16. Moon, J.; Kim, G.; Lee, S. A Gold Nanoparticle and Aflatoxin B1-BSA Conjugates Based Lateral Flow Assay Method for the Analysis of Aflatoxin B1. Materials 2012, 5, 634-643. [CrossRef]

17. Salah Eldin, T.A.; Elshoky, H.A.; Ali, M.A. Nanobiosensor based on gold nanoparticles probe for Aflatoxin B1 detection in food. Int. J. Curr. Microbiol. Appl. Sci. 2014, 3, 219-230.

18. Evtugyn, G.; Hianik, T. Electrochemical Immuno- and Aptasensors for Mycotoxin Determination. Chemosensors 2019, 7, 10. [CrossRef]

19. Xiao, T.; Huang, J.; Wang, D.; Meng, T.; Yang, X. Au and Au-Based nanomaterials: Synthesis and recent progress in electrochemical sensor applications. Talanta 2020, 206, 120210. [CrossRef]

20. Hu, H.; Cao, L.; Li, Q.; Ma, K.; Yan, P.; Kirk, D.W. Fabrication and modeling of an ultrasensitive label free impedimetric immunosensor for Aflatoxin B1based on poly(o-phenylenediamine) modified gold 3D nano electrode ensembles. RSC Adv. 2015, 5, 55209-55217. [CrossRef]

21. Karimian, N.; Moretto, L.M.; Ugo, P. Nanobiosensing with Arrays and Ensembles of Nanoelectrodes. Sensors 2016, 17, 65. [CrossRef]

22. Bottari, F.; Oliveri, P.; Ugo, P. Electrochemical immunosensor based on ensemble of nanoelectrodes for immunoglobulin IgY detection: Application to identify hen's egg yolk in tempera paintings. Biosens. Bioelectron. 2014, 52, 403-410. [CrossRef] [PubMed]

23. Chauhan, R.; Basu, T. Functionalised Au Coated Iron Oxide Nanocomposites Based Reusable Immunosensor for AFB1 Detection. J. Nanomater. 2015, 2015, 607268. [CrossRef]

24. Luan, Y.; Chen, Z.; Xie, G.; Chen, J.; Lu, A.; Li, C.; Fu, H.; Ma, Z.; Wang, J. Rapid Visual Detection of Aflatoxin B1 by Label-Free Aptasensor Using Unmodified Gold Nanoparticles. J. Nanosci. Nanotechnol. 2015, 15, 1357-1361. [CrossRef] [PubMed]

25. Wang, X.; Niessner, R.; Knopp, D. Magnetic Bead-Based Colorimetric Immunoassay for Aflatoxin B1 Using Gold Nanoparticles. Sensors 2014, 14, 21535-21548. [CrossRef] 
26. Hosseini, M.; Khabbaz, H.; Dadmehr, M.; Ganjali, M.R.; Mohamadnejad, J. Aptamer-based Colorimetric and Chemiluminescence Detection of Aflatoxin B1 in Foods Samples. Acta Chim. Slov. 2015, 62, 721-728. [CrossRef] [PubMed]

27. Abhijith, K.S.; Thakur, M.S. Application of green synthesis of gold nanoparticles for sensitive detection of aflatoxin B1 based on metal enhanced fluorescence. Anal. Methods 2012, 4, 4250-4256. [CrossRef]

28. Majzik, A.; Hornok, V.; Sebők, D.; Bartók, T.; Szente, L.; Tuza, K.; Dékány, I. Sensitive detection of aflatoxin B1 molecules on gold SPR chip surface using functionalized gold nanoparticles. Cereal Res. Commun. 2015, 43, 426-437. [CrossRef]

29. Akgönüllü, S.; Yavuz, H.; Denizli, A. SPR nanosensor based on molecularly imprinted polymer film with gold nanoparticles for sensitive detection of aflatoxin B1. Talanta 2020, 219, 121219. [CrossRef]

30. Kour, R.; Arya, S.; Young, S.-J.; Gupta, V.; Bandhoria, P.; Khosla, A. Review-Recent Advances in Carbon Nanomaterials as Electrochemical Biosensors. J. Electrochem. Soc. 2020, 167, 037555. [CrossRef]

31. Song, C.; Wei, Q.; Li, H.; Gao, H.; An, J.; Qi, B. Highly Sensitive Electrochemical Sensor based on Carbon Dots Reduced Gold Nanoparticles for Ractopamine Detection in Pork Meat. Int. J. Electrochem. Sci. 2020, 15, 3495-3503. [CrossRef]

32. Guo, W.; Pi, F.; Zhang, H.; Sun, J.; Zhang, Y.; Sun, X. A novel molecularly imprinted electrochemical sensor modified with carbon dots, chitosan, gold nanoparticles for the determination of patulin. Biosens. Bioelectron. 2017, 98, 299-304. [CrossRef] [PubMed]

33. Masikini, M.; Ghica, M.E.; Baker, P.G.L.; Iwuoha, E.I.; Brett, C.M. Electrochemical Sensor Based on Multi-walled Carbon Nanotube/Gold Nanoparticle Modified Glassy Carbon Electrode for Detection of Estradiol in Environmental Samples. Electroanalysis 2019, 31, 1925-1933. [CrossRef]

34. Zhang, S.; Shen, Y.; Shen, G.; Wang, S.; Shen, G.; Yu, R. Electrochemical immunosensor based on Pd-Au nanoparticles supported on functionalized PDDA-MWCNT nanocomposites for aflatoxin B1 detection. Anal. Biochem. 2016, 494, 10-15. [CrossRef] [PubMed]

35. Chikkaveeraiah, B.V.; Bhirde, A.; Malhotra, R.; Patel, V.; Gutkind, J.S.; Rusling, J.F.; Chikkaveeraih, B.V. Single-Wall Carbon Nanotube Forest Arrays for Immunoelectrochemical Measurement of Four Protein Biomarkers for Prostate Cancer. Anal. Chem. 2009, 81, 9129-9134. [CrossRef] [PubMed]

36. Pan, D.; Gu, Y.; Lan, H.; Sun, Y.; Gao, H. Functional graphene-gold nano-composite fabricated electrochemical biosensor for direct and rapid detection of bisphenol A. Anal. Chim. Acta 2015, 853, 297-302. [CrossRef] [PubMed]

37. AlThagafi, I.I.; Ahmed, S.A.; El-Said, W.A. Fabrication of gold/graphene nanostructures modified ITO electrode as highly sensitive electrochemical detection of Aflatoxin B1. PLoS ONE 2019, 14, e210652. [CrossRef]

38. Hamzah, H.H.; Shafiee, S.A.; Abdalla, A.; Patel, B.A. 3D printable conductive materials for the fabrication of electrochemical sensors: A mini review. Electrochem. Commun. 2018, 96, 27-31. [CrossRef]

39. Xu, Y.; Xu, Y.; Gao, C.; Duan, X. Three-dimensional macro-structures of two-dimensional nanomaterials. Chem. Soc. Rev. 2016, 45, 5541-5588. [CrossRef]

40. Zou, L.; Qiao, Y.; Wu, Z.-Y.; Wu, X.-S.; Xie, J.-L.; Yu, S.-H.; Guo, J.; Li, C.M. Tailoring Unique Mesopores of Hierarchically Porous Structures for Fast Direct Electrochemistry in Microbial Fuel Cells. Adv. Energy Mater. 2015, 6, 1501535. [CrossRef]

41. Liang, T.; Zou, L.; Guo, X.; Ma, X.; Zhang, C.; Zou, Z.; Zhang, Y.; Hu, F.; Lu, Z.; Tang, K.; et al. Rising Mesopores to Realize Direct Electrochemistry of Glucose Oxidase toward Highly Sensitive Detection of Glucose. Adv. Funct. Mater. 2019, 29. [CrossRef]

42. Hu, X.; Wang, T.; Qu, X.; Dong, S. In Situ Synthesis and Characterization of Multiwalled Carbon Nanotube/Au Nanoparticle Composite Materials. J. Phys. Chem. B 2006, 110, 853-857. [CrossRef] [PubMed]

43. Wang, D.; Hu, W.; Xiong, Y.; Xu, Y.; Li, C.M. Multifunctionalized reduced graphene oxide-doped polypyrrole/pyrrolepropylic acid nanocomposite impedimetric immunosensor to ultra-sensitively detect small molecular aflatoxin B 1. Biosens. Bioelectron. 2015, 63, 185-189. [CrossRef] [PubMed]

44. Wei, H.; Wu, X.-S.; Zou, L.; Wen, G.-Y.; Liu, D.-Y.; Qiao, Y. Amine-terminated ionic liquid functionalized carbon nanotubes for enhanced interfacial electron transfer of Shewanella putrefaciens anode in microbial fuel cells. J. Power Sources 2016, 315, 192-198. [CrossRef]

45. Liu, L.; Chao, Y.; Cao, W.; Wang, Y.; Luo, C.; Pang, X.; Fan, D.; Wei, Q. A label-free amperometric immunosensor for detection of zearalenone based on trimetallic Au-core/AgPt-shell nanorattles and mesoporous carbon. Anal. Chim. Acta 2014, 847, 29-36. [CrossRef] [PubMed]

46. Bhardwaj, H.; Pandey, M.K.; Rajesh; Gajjala, S. Electrochemical Aflatoxin B1 immunosensor based on the use of graphene quantum dots and gold nanoparticles. Microchim. Acta 2019, 186, 592. [CrossRef]

47. Afkhami, A.; Hashemi, P.; Bagheri, H.; Salimian, J.; Ahmadi, A.; Madrakian, T. Impedimetric immunosensor for the label-free and direct detection of botulinum neurotoxin serotype A using Au nanoparticles/graphene-chitosan composite. Biosens. Bioelectron. 2017, 93, 124-131. [CrossRef]

48. Cheli, F.; Pinotti, L.; Rossi, L.; Dell'Orto, V. Effect of milling procedures on mycotoxin distribution in wheat fractions: A review. LWT 2013, 54, 307-314. [CrossRef]

49. Sharma, A.; Kumar, A.; Khan, R. A highly sensitive amperometric immunosensor probe based on gold nanoparticle functionalized poly (3, 4-ethylenedioxythiophene) doped with graphene oxide for efficient detection of aflatoxin B 1. Synth. Met. 2018, 235, 136-144. [CrossRef]

50. Ma, H.; Sun, J.; Zhang, Y.; Xia, S. Disposable amperometric immunosensor for simple and sensitive determination of aflatoxin B 1 in wheat. Biochem. Eng. J. 2016, 115, 38-46. [CrossRef] 
51. Ma, H.; Sun, J.; Zhang, Y.; Bian, C.; Xia, S.; Zhen, T. Label-free immunosensor based on one-step electrodeposition of chitosan-gold nanoparticles biocompatible film on Au microelectrode for determination of aflatoxin B1 in maize. Biosens. Bioelectron. 2016, 80, 222-229. [CrossRef]

52. Shi, L.; Wang, Z.; Yang, G.; Chen, X.; Gou, G.; Liu, W. Electrochemical Immunosensor for Aflatoxin B1 Based on Polyaniline/Graphene Nanohybrids Decorated with Au Nanoparticle. Electrochemistry 2017, 85, 384-390. [CrossRef]

53. Owino, J.H.; Arotiba, O.A.; Hendricks, N.; Songa, E.A.; Jahed, N.; Waryo, T.T.; Ngece, R.F.; Baker, P.G.L.; Iwuoha, E. Electrochemical Immunosensor Based on Polythionine/Gold Nanoparticles for the Determination of Aflatoxin B1. Sensors 2008, 8, 8262-8274. [CrossRef] [PubMed]

54. Sun, A.-L.; Qi, Q.-A.; Dong, Z.-L.; Liang, K.Z. An electrochemical enzyme immunoassay for aflatoxin B1 based on bioelectrocatalytic reaction with room-temperature ionic liquid and nanoparticle-modified electrodes. Sens. Instrum. Food Qual. Saf. 2008, 2, 43-50. [CrossRef]

55. Li, S.C.; Chen, J.H.; Cao, H.; Yao, D.S.; Liu, D.L. Amperometric biosensor for aflatoxin B1 based on aflatoxin-oxidase immobilized on multiwalled carbon nanotubes. Food Control. 2011, 22, 43-49. [CrossRef]

56. European Commission. Commission Decision of 12 August 2002 implementing Council Directive 96/23/EC concerning the performance of analytical methods and the interpretation of results (2002/657/EC). Off. J. Eur. Commun. 2002, 221, 8-36. 